\title{
RBEP
}

\section{Formação continuada e ensino da escrita: análise de estratégias formativas utilizadas no programa Pró-Letramento}

Telma Ferraz Leal

Andrea Tereza Brito Ferreira

\section{Resumo}

Objetiva discutir sobre estratégias formativas utilizadas no programa Pró-Letramento. Foram analisados 152 relatórios de 24 orientadores de estudo do Rio de Janeiro e do Rio Grande do Sul. Os resultados apontaram que esses orientadores, muitos ainda iniciantes nesta função de "desenvolver experiências de formação docente", evidenciaram capacidade de favorecer, entre seus pares, situações de aprendizagem ancoradas em saberes construídos no cotidiano da escola.

Palavras-chave: formação continuada; ensino da escrita; produção de textos.

\section{Abstract}

Continuing Education and the teaching of writing: an analysis of the Pró-Letramento Program strategies of education

The paper aimed at the education strategies of the Pró-Letramento Program. There were analyzed 152 reports of 24 tutors from Rio de Janeiro and Rio Grande do Sul. The results pointed out that these 
tutors, sometimes still beginning to act as a person responsible for the development of teacher education experiences, have a capacity to contribute to teaching and learning situations based on school knowledge.

Keywords: continuing education; teaching of writing; texts production.

O que um professor precisa saber para ensinar a ler e escrever? O que é importante contemplar nos cursos de formação inicial e continuada para que os docentes tenham condições de fazer um trabalho de qualidade?

Nos primeiros documentos oficiais que recrutavam pessoas para o exercício da docência (Lei Imperial de 1894), o professor deveria saber apenas ler, escrever e fazer as quatro operações da aritmética. Ao longo dos anos, com as diversas mudanças nas concepções de ensino e aprendizagem, esse perfil foi sendo alterado. Passou-se a exigir que o profissional, no mínimo, tivesse uma formação inicial contendo vários conhecimentos voltados para o ato de ensinar, até então pouco valorizados. Com as mudanças nas concepções, o ensino da leitura e da escrita ganhou status diferenciado, sendo reconhecido como um trabalho complexo que exige diferentes tipos de saberes e capacidades.

Ensinar a ler e escrever, de fato, é uma tarefa complexa, tanto quanto aprender a ler e escrever. Para aprender a ler e escrever não é necessário apenas ter contato com materiais escritos ou saber regras; é preciso aprender a lidar com diferentes práticas sociais, a construir representações sobre as situações sociais nas quais estamos inseridos. Muitos estudiosos, como Chartier (2007, 2010), Goigoux (2007) e Solé (1998), buscam mostrar como a escola pode desenvolver práticas pedagógicas que levem os sujeitos a se tornarem leitores e escritores autônomos. Tais mudanças exigem dos professores um repensar no seu fazer pedagógico, que pode ser favorecido por meio da formação inicial, mas também, e sobretudo, por meio da formação continuada.

Para contribuirmos com este debate, buscamos analisar uma experiência de formação continuada (programa Pró-Letramento), por meio da exploração dos relatórios elaborados por orientadores de estudo do Rio de Janeiro e do Rio Grande do Sul. Antes, porém, faremos uma breve discussão sobre as mudanças no ensino da língua materna no País.

\section{Mudanças no ensino da língua materna}

Durante muito tempo predominou uma concepção de língua apenas como um sistema de códigos. Essa maneira de conceber a língua contribuiu para a organização do ensino com o enfoque apenas no domínio das 
regras fonológicas, lexicais e sintáticas, ficando de fora o sujeito que fala, bem como o contexto no qual este se insere.

A partir dos anos 1980, estudos efetuados por muitos teóricos conduziram-nos à concepção de língua como um fenômeno heterogêneo, variável, histórico e social, indeterminado, situacional, sistemático e cognitivo, conforme nos afirma Marcuschi (2005). Com base em diferentes autores, como Bakhtin (1998), a língua passa a ser entendida como um fenômeno social de interação.

No entanto, ainda hoje podemos perceber que, quando nos reportamos ao ensino da leitura, são relatadas muitas práticas em conformidade com a concepção de língua como sistema abstrato de regras com propostas de atividades dissociadas dos diversos usos sociais da escrita. Contudo, paralelamente a tais práticas, são também vivenciadas situações em que se toma a língua como atividade de interação entre dois ou mais interlocutores. Sinaliza-se, nessas práticas, uma concepção em que a leitura é concebida como "um processo de interlocução entre leitor/autor mediado pelo texto. Encontro com o autor, ausente, que se dá pela sua palavra escrita" (Geraldi, 2003).

Na realidade, essas práticas muitas vezes convivem em um mesmo espaço educacional e, ainda, em uma mesma prática docente; isto é, no cotidiano da sala de aula muitos professores, na busca de responder suas próprias indagações sobre como ajudar os estudantes a aprender, fazem tentativas que, do ponto de vista dos modelos teóricos, seriam contraditórias. Esses fenômenos, efetivamente, expressam o desejo do professor de buscar caminhos para responder às demandas. A procura de uma coerência pragmática faz com que determinadas escolhas sejam aos poucos abandonadas e outras persistam, em decorrência das avaliações que os docentes fazem das consequências de suas ações. Assim, "o professor tem que fazer escolhas em função de situações específicas e, apenas ele, com base na sua experiência, poderá decidir qual caminho seguir para atingir seus objetivos" (Ferreira, 2005, p. 63).

O docente, desse modo, "filtra" as informações a que tem acesso em diferentes fontes bibliográficas e espaços de formação e de atuação e seleciona aquilo que, "aos seus olhos", vai ser mais importante para melhorar as situações didáticas que promove.

Neste artigo, defendemos que a formação continuada de professores pode contribuir para que novas formas de pensar o ensino da leitura e da escrita sejam fabricadas pelos docentes. Por meio da formação continuada, é possível construir diversos saberes coletivamente. No entanto, podemos nos questionar sobre quais princípios pedagógicos e quais estratégias formativas seriam potencialmente favoráveis a tais aprendizagens. É o que discutiremos nos tópicos a seguir.

\section{Formação continuada e ensino da língua portuguesa}

Discutir sobre formação continuada é uma tarefa hoje difícil, embora a literatura venha crescendo na área. Muitos estudos vêm sendo realizados 
na busca de compreender quais são os saberes docentes indispensáveis a uma prática pedagógica consistente, como os saberes docentes são construídos e que políticas públicas de formação docente são favoráveis à melhoria do ensino. Além dessas questões, é fundamental entender que as mudanças didáticas e pedagógicas acontecem de forma diferente com cada professor, em decorrência de suas experiências prévias e conhecimentos já consolidados. Chartier (2010, p. 57) atenta, por exemplo, que um professor que já atua no magistério

\begin{abstract}
pode vir a se tornar um praticante "reflexivo", já que ele domina uma prática a partir da qual pode refletir. Por outro lado, um professor novato capaz de verbalizar uma situação pedagógica, de relacioná-la aos textos oficiais, às prescrições didáticas e de fazer uma análise crítica dela, pode ser incapaz de colocá-las em ação, pois lhe falta o saber fazer da prática.
\end{abstract}

Nessa perspectiva, é indispensável, ao refletirmos sobre formação de professores, valorizarmos não apenas os saberes oriundos das situações de apreensão de conceitos e modelos teóricos, mas também os que são gerados na prática cotidiana, tal como vem sendo defendido por muitos autores (Houpert, 2005; Tardif, 2000; Nóvoa, 1995). É preciso, neste modo de conceber a formação docente, reconhecer que nem um e nem outro tipo de saber é suficiente por si. Na formação continuada, sobretudo, a riqueza reside justamente na articulação entre essas duas fontes de conhecimento.

Leal, Guimarães e Silva (2001) conduziram e analisaram um projeto de formação continuada em que tais tipos de saberes eram constantemente mobilizados e postos em confronto. As autoras analisaram os resultados relativos a duas escolas, num total de 20 observações dos encontros de formação (11 na escola A e 9 na B). Os encontros eram gravados, para posterior análise, e as professoras eram entrevistadas durante todo o ano de execução do projeto.

As análises das atividades de formação realizadas nas escolas evidenciaram que foram desenvolvidos diferentes tipos de estratégias formativas.

Uma atividade frequente era a de análise e discussão de relatórios de aulas:

Eram entregues relatórios de aulas previamente selecionados, para que as professoras refletissem sobre as situações didáticas de produção, analisando e discutindo sobre a condução das aulas, sobre os comandos dados, a qualidade das informações disponibilizadas durante a aula, a mediação dos professores, etc. (Leal, Guimarães, Silva, 2001, p. 117).

Outro tipo de atividade consistia na proposição de situações de produção de textos e reflexões sobre as estratégias usadas para construí-los, as dificuldades e as decisões tomadas durante a escrita:

As professoras recebiam comandos para produzir textos e a partir de suas produções discutiam sobre a própria atividade de geração do texto e sobre as características dos gêneros que lhes eram solicitados. Assim, as professoras se reconheciam enquanto sujeitos constituídos e 
constituintes das práticas de linguagem, compreendiam as dificuldades dos alunos e a importância da mediação. (Leal, Guimarães, Silva, 2001, p. 117-118).

Atividades de análise de textos de circulação social também foram realizadas. Nesses momentos, eram levados textos de diferentes gêneros, que eram lidos pelo grupo. Após a leitura, as docentes tentavam sistematizar características e aspectos que poderiam ser foco de reflexão no ensino da leitura/produção. Assim como os textos de circulação social, os das crianças também eram analisados, muitas vezes, em comparação com aqueles.

A discussão sobre os critérios de avaliação e sobre as dificuldades próprias dos produtores iniciantes era realizada conjuntamente à discussão sobre os comandos dados e sobre o planejamento didático. Assim, buscava-se levar a professora a pensar tanto nos aspectos comunicativo-enunciativos quanto nos aspectos formais. (Leal, Guimarães, Silva, 2001, p. 118).

As situações de planejamento coletivo de aulas também foram frequentes nos encontros de formação. As professoras, em grupo, planejavam aulas para atender a diferentes objetivos didáticos previamente acordados entre elas e para mobilizar determinadas habilidades e conhecimentos enfocados na formação. Os planejamentos eram socializados e as discussões eram feitas por meio da mobilização dos conceitos e teorias discutidos.

Outra estratégia formativa adotada, embora com menor frequência, era a análise de situações didáticas expostas em programas de vídeos. Por fim, também foram realizadas muitas exposições dialogadas, em que as formadoras sistematizavam conceitos, teorias e abordagens teóricas.

Apesar da grande variedade de estratégias formativas, as autoras problematizaram as ações desenvolvidas, evidenciando que muitas tensões foram vivenciadas durante os encontros.

Os conflitos resultavam, principalmente, do confronto entre as concepções de ensino de produção de textos vigentes no espaço escolar e as concepções propostas no projeto em desenvolvimento. O depoimento de uma das professoras ressalta tal tensão:

Não tendo domínio da escrita não poderia trabalhar com textos. Achava que o aluno não era capaz, pois antes precisava aprender as letras, as sílabas, as palavras, frases... no final terminava em texto. (Depoimento de uma professora apud Leal, Guimarães, Silva, 2001, p. 120).

Essa angústia foi vivenciada também por outras docentes, que desenvolviam um ensino centrado principalmente no treino de padrões silábicos, em que os estudantes aprendiam as unidades menores da língua (letras, sílabas) e apenas após dominarem tais unidades seriam expostos a unidades textuais. Isto é, foi possível constatar que algumas professoras se depararam, na formação, com princípios teórico-metodológicos que contradiziam suas práticas e concepções. 
O relato das tensões acima expostas evidencia que a formação do professor é um fenômeno complexo e multifacetado e que tensões são sempre presentes, sobretudo, porque não existe neutralidade no processo educativo. Os conflitos, no entanto, podem ser mais ou menos agravados em função do tipo de relação que se estabelece entre os integrantes do grupo e entre cursistas e formadores.

Foi verificado que em um projeto de formação continuada centrado na prática docente, como o que foi aqui citado, com situações de análise de experiências docentes, situações de planejamento conjunto e socialização de experiências, a consciência das dificuldades pode favorecer que diferentes práticas sejam confrontadas, o que, sem dúvida, possibilita a emergência de tensões. Por outro lado, favorece, também, o repensar do cotidiano e a reconstrução de saberes.

Esse tipo de formação pode motivar o professor "a perceber esse momento como um aprendizado, no qual a sua experiência é tão importante quanto o que está sendo colocado como 'novos desafios' para o ensino de produção textual" (Ferreira, 2005, p. 63).

É fundamental, portanto, em qualquer processo formativo, tentar entender a origem do saber docente e reconhecer os conhecimentos construídos, valorizando suas experiências. No projeto de pesquisa citado, foi possível perceber, por meio dos depoimentos mencionados pelas autoras, que, ao longo dos encontros de formação, os acordos foram se estabelecendo e as professoras ganharam mais confiança nas formadoras e nos seus próprios saberes, de modo que, no final do curso, demonstraram satisfação em terem superado tais níveis de tensão iniciais.

\begin{abstract}
Esse projeto aqui na escola pra mim foi assim... Veio de acordo com meus pensamentos, com minhas ideias, porque os outros lá fora sempre tem alguma coisa que eu questiono, e aqui não houve esse questionamento de minha parte. Quer dizer, havia muitas dúvidas, muitas coisas que eu desconhecia... Eu uso, mas não sei dar o nome. Mas a diferença é essa: lá fora eles impõem um modelo único para todo mundo e eu não aceito isso. (Depoimento de uma professora apud Leal, Guimarães, Silva, 2001, p. 122).
\end{abstract}

No extrato acima, destacamos outro critério usado pelas docentes para julgar os programas de formação. Para elas, um bom processo formativo não pode impor de maneira unilateral o que o professor tem que fazer:

O clima de confiança e de cumplicidade foi construído porque, conforme indica a fala da professora, não havia imposição do que deveria ser feito. Todos os temas eram discutidos a partir do que elas faziam, mas sempre numa atitude construtiva em que as próprias professoras, a partir do acesso aos conceitos e modelos teóricos sobre os temas, teorizavam e chegavam às suas próprias conclusões. (Leal, Guimarães, Silva, 2001, p. 122-123)

Em suma, as análises das entrevistas apontaram dois principais critérios para a avaliação que as docentes faziam do que seria um bom projeto de formação continuada: 1) o respeito aos modos de pensar das 
professoras; 2) a não imposição sobre o que as professoras tinham que fazer em sala de aula. Subjacente a todas as falas, havia uma aceitação/ aprovação do modelo de formação centrado na prática docente. As professoras achavam sempre positivo o fato de tratarem a teoria de modo bastante articulado ao dia a dia da sala de aula.

Nesta pesquisa, cujo campo de investigação foi um programa do governo federal - o Pró-Letramento -, analisamos se as estratégias formativas adotadas seguiam os mesmos princípios formativos discutidos neste tópico, investigando a articulação entre tais estratégias e os temas mais valorizados pelos orientadores de estudo.

\section{O programa Pró-Letramento: relatos e reflexões sobre a formação de professores}

O programa Pró-Letramento tem como objetivos principais oferecer suporte à ação pedagógica dos professores dos anos iniciais do ensino fundamental, para elevar a qualidade do ensino e da aprendizagem da língua portuguesa; propor situações que incentivem a reflexão e a construção do conhecimento como processo contínuo de formação docente; desenvolver conhecimentos que possibilitem a compreensão da linguagem e seus processos de ensino e aprendizagem.

É um programa desenvolvido em parceria com universidades e Secretarias de Educação (SEEs). O Ministério da Educação (MEC), para desenvolver tal programa, convidou algumas universidades públicas. Apesar de o material básico ser comum a todos os Estados, cada universidade tem autonomia para planejar sua intervenção e organizar a dinâmica de funcionamento da ação, adotando as estratégias didáticas que considerarem mais adequadas.

As universidades realizam a formação e o acompanhamento de orientadores de estudo (profissionais do quadro efetivo das SEEs, denominados pelo MEC de tutores), que são responsáveis por coordenar os encontros de formação com os professores em seus municípios.

Nesta pesquisa, focaremos a experiência de formação no âmbito deste projeto nos Estados do Rio de Janeiro, em 2007, e do Rio Grande do Sul, em 2008-2009. Esses Estados, no período investigado, foram atendidos pela Universidade Federal de Pernambuco (UFPE).

A metodologia adotada constou da análise dos planejamentos dos formadores que atuavam diretamente com os orientadores de estudo e de relatórios elaborados pelos orientadores de estudo que eram responsáveis pelos encontros ocorridos nos municípios. Para maior clareza sobre as condições de produção desses documentos, apresentaremos, a seguir, algumas informações sobre a dinâmica de funcionamento do programa.

A UFPE realizava encontros pedagógicos com os orientadores de estudo, conduzidos por professores dessa instituição e de outras universidades parceiras (Universidade Federal do Rio de Janeiro, Universidade do Vale do Rio dos Sinos, Fundação Universidade Regional de Blumenau), num total de 96 
horas na etapa 1 e de 64 horas na etapa 2. Esses orientadores coordenavam os grupos de estudo nos municípios sob monitoramento da universidade, o qual se dava pelos relatos e planejamentos discutidos nos encontros de formação e mediante análise dos relatórios elaborados pelos próprios orientadores de estudo. O programa era organizado em sete unidades que tinham como material de apoio um fascículo contendo texto teórico para estudo. A recomendação feita aos orientadores de estudo era para que desenvolvessem cada fascículo em três encontros de quatro horas. Para cada unidade do curso (três encontros), os orientadores deveriam elaborar um relatório de reflexão sobre as atividades realizadas. Desse modo, deveriam entregar, ao longo de uma etapa de formação, sete relatórios.

Por meio da leitura dos planejamentos dos encontros de formação dos orientadores de estudo ministrados pelos professores das universidades, foi possível verificar que diferentes temáticas foram abordadas nos encontros pedagógicos, como currículo, avaliação, alfabetização, letramento, leitura, biblioteca, produção de textos, oralidade e recursos didáticos para o ensino da língua (jogos e livros didáticos). Muitas estratégias formativas foram também contempladas: leitura deleite, análise de relatos de aulas de professores, análise de textos de crianças, planejamento de aulas, vídeo em debate, entre outras. Tal diversidade foi avaliada positivamente pelos orientadores de estudo, que relataram situações vivenciadas em seus municípios inspiradas em algumas experiências dos encontros de formação com os formadores da universidade.

Mediante a análise dos relatórios elaborados pelos orientadores de estudo, buscamos identificar as temáticas mais trabalhadas nos encontros que eles tiveram com os professores e, também, as estratégias formativas adotadas por estes. Foram analisados 152 relatórios de encontros pedagógicos de 24 orientadores de estudo.

Segundo os dados apresentados nos relatórios, a leitura foi um dos temas mais recorrentes nos encontros de formação com os professores, tendo sido abordada por meio de diferentes estratégias formativas, das quais a mais citada nos relatórios (em todos) foi a denominada pelos formadores e cursistas de leitura deleite. Nos encontros de formação destinados aos orientadores de estudo, foram realizadas leituras, todos os dias, com o objetivo de despertar o prazer de ouvir e/ou fazer uma leitura. Para esses momentos, eram escolhidos textos que tentavam seduzir, ou melhor, encantar os orientadores, seja pela relevância da temática, seja pelos recursos expressivos/estéticos ou pelos efeitos de humor que causavam. Geralmente, eram utilizadas crônicas, poesias, músicas, memórias etc. Os orientadores passaram a usar esta mesma estratégia nos encontros com os professores.

As cursistas manifestavam interesse pela leitura deleite e muitas delas comentavam e levavam para as suas salas de aula. (Rosméri Hermes).

Houve a constatação de que o trabalho diário com leitura e escrita é o que objetivará a familiaridade e a compreensão de diferentes assuntos e gêneros textuais. (Adriane Angheben Eitelven). 
A leitura deleite é uma das atividades mais esperadas pelas professoras principalmente por ser sempre uma novidade. As professoras passaram a adotar a leitura deleite como atividade permanente em sua rotina. (Neiva Xavier Barasuol).

A leitura deleite promoveu um aumento na procura de títulos nas bibliotecas das escolas. As professoras esperavam ansiosas pela leitura deleite. (Adriana Sartori).

As cursistas da área de matemática estão fazendo leitura deleite com seus alunos, influenciadas pelas colegas da área de linguagem. (Lília Jurema Monteiro Masson).

Os extratos dos relatórios evidenciam o quanto a estratégia formativa usada nos encontros com os orientadores de estudo foi valorizada pelos cursistas, que levaram para seus encontros de estudo com os professores. Entre outros aspectos positivos ligados a este tipo de atividade, foram ressaltadas a ampliação do acervo textual dos professores, a conscientização acerca do quanto aprendemos quando ouvimos e conversamos sobre os textos lidos e a possibilidade de levar os ouvintes a buscar novas obras para ler. Nos relatórios também apareciam depoimentos de que os professores estavam adotando esse tipo de estratégia em suas salas de aula na educação básica. Tal opção provavelmente decorreu da "aposta" de que, como eles aprenderam quando estiveram na posição de ouvintes dos textos, os alunos também teriam o que aprender.

É interessante citar que havia uma transferência desse tipo de estratégia formativa (ler textos literários para os orientadores) dos encontros de formação dos orientadores de estudo para os encontros com os docentes, e destes para as aulas na educação básica. No entanto, não havia uma mera repetição, pois os orientadores modificavam a condução da atividade.

Esta estratégia - leitura deleite - sofreu acréscimos interessantes. Por exemplo, a orientadora Margarida Pap, da Secretaria Estadual de Educação do Rio de Janeiro, relatou uma experiência que constava de situações em que os participantes de um grupo selecionavam textos dos quais gostavam e levavam para compor uma sacola de textos, que era usada pelos professores sequencialmente. Cada docente ficava com a sacola durante um tempo, realizando atividades com os estudantes. Nos encontros de estudo, socializavam os modos como os textos foram trabalhados em sala de aula. Essa experiência foi socializada no Rio Grande do Sul e uma orientadora naquele Estado relatou uma experiência exitosa de sacola deleite em turmas da educação básica.

As alunas relataram, após o término da atividade, como foi o uso da sacola deleite em sua turma. Algumas estavam muito empolgadas, dizendo que a sacola terá de fazer parte de sua aula. A maioria gostou bastante e disse não estar confiante que daria certo, mas que o resultado as surpreendeu. Algumas relataram a reação das crianças ao uso da sacola e de como eles esperavam pela leitura. (Jaqueline de Oliveira dos Santos). 
Estas e outras atividades tinham como propósito despertar os cursistas e os alunos para a leitura do texto literário. No entanto, a leitura também aparecia nos relatórios para atender a outras finalidades:

[...] eu leio todo dia na sala de aula. Por que é impossível o professor não ler, não é mesmo? Mas com esse cuidado no que vai despertar nos alunos é que é diferente [...]. (Marcela, professora de Barra Mansa).

Os debates relatados pelos orientadores de estudo conduziam a uma tomada de consciência de que diferentes habilidades estão envolvidas no ato de ler e que a compreensão leitora ocorre por meio de diferentes estratégias. Esse princípio é reincidentemente retomado no material de apoio usado no programa. Fica claro, nos fascículos, que é importante considerar a leitura como um processo de construção de sentido, mediante o qual o leitor reconstrói o texto. Outra orientadora de estudos mostra que ter vivenciado experiências diversificadas de leitura nos encontros pedagógicos favoreceu a compreensão de que é preciso explorar os textos de diferentes maneiras.

Eu nunca dava muita importância para o levantamento dos conhecimentos prévios ou de antecipação do texto com os alunos quando ia trabalhar leitura. Vejo que é uma forma de despertar a curiosidade dos alunos e envolvê-los na leitura. (Michele, tutora de Armação de Búzios).

Outro aspecto muito ressaltado pelos orientadores de estudo foi a adoção da ideia de que a biblioteca e os cantinhos de leitura precisam ser espaços lúdicos de formação de leitores.

Durante as avaliações, os cursistas consideraram importante o resgate do uso de bibliotecas por resgatar o contato com diversos gêneros textuais. (Mára Rejane Pioner Gomes).

As cursistas trocavam experiências sobre como organizar um pequeno acervo na sala de aula e, também, como organizar empréstimos e manuseios dos livros. (Lilia Jurema Monteiro Masson).

Os professores cujas escolas não possuíam biblioteca organizaram o cantinho da leitura. (Ione Maria Lindorfer).

Uma terceira ideia presente nos relatórios foi a de que a aprendizagem da língua portuguesa deve visar à inserção nos diferentes espaços sociais de interlocução. Os orientadores de estudo ressaltaram que, por meio das discussões emergentes nas atividades de analisar relatos de aulas de professores e planejar coletivamente, perceberam que é preciso contemplar variadas situações de leitura, produção e reflexão sobre diferentes gêneros discursivos. No entanto, a atividade de analisar textos de circulação social, buscando refletir sobre suas características e possíveis objetivos didáticos a serem atingidos por meio de atividades de exploração desses textos, foi aceita com muita empolgação. 
A atividade mais gostosa dos encontros foi a análise dos diferentes gêneros textuais, a partir do quadro comparativo proposto no encontro presencial do Pró-Letramento. (Sílvia Regina Cavalheiro Zangirolami).

As atividades faziam surgir ideias por parte dos cursistas. Inclusive comentaram que nunca haviam realizado uma atividade de análise de gêneros textuais. (Rosméri Hermes).

O princípio da ludicidade também foi evidenciado pelos orientadores de estudo como tendo sido um tema relevante dos encontros com os professores. Segundo eles, os professores passaram a se preocupar mais com a motivação das crianças, ou seja, reconheciam que a aprendizagem pode e deve acontecer de maneira prazerosa e que, por isso, é preciso planejar situações lúdicas de ensino. Também em relação a esse aspecto, citaram estratégias formativas que vivenciaram nos encontros de formação.

A atividade de construção de jogos a partir da análise de protocolos mostrou-se bem prazerosa, porque eles trocaram ideias durante a elaboração e apresentaram sugestões de variações. (Patrícia Geyer).

As dinâmicas aplicadas durante o curso fizeram a tutora e os cursistas perceberem que é possível aprender brincando, até mesmo os professores. A atividade de confecção de jogos proporcionou momentos de integração e questionamentos. (Adriana Sartori).

As atividades práticas envolvendo jogos foram bem aceitas pelo grupo, tanto que, para algumas delas, o encontro em que construíram jogos pedagógicos foi considerado o melhor. (Lília Jurema Monteiro Masson).

Nos encontros de formação dos orientadores de estudo, também foram abordados temas relativos ao uso de variados recursos didáticos. Nos relatórios, aparecia, com frequência, a referência a atividades que tinham objetivos de fazer os professores perceberem que a seleção e o uso de bons e variados recursos didáticos são pré-requisitos para a condução de situações de aprendizagem significativas.

Durante as discussões, as cursistas perceberam que o uso do dicionário pode ser ampliado conforme as proposições do curso. (Rosméri Hermes).

Os cursistas chegaram à conclusão de que o dicionário é um instrumento importante, mas que muitas vezes não sabemos utilizá-lo. (Carla Adriana da Costa Peukert).

O tira-dúvidas sobre a nova ortografia e as atividades com dicionário propiciaram uma troca significativa sobre este recurso pouco utilizado em sala de aula. (Selma de Souza da Silva).

A avaliação também foi objeto de atenção no programa. Entre outras estratégias didáticas, foram promovidas situações em que os orientadores de estudo analisavam e elaboravam instrumentos de avaliação. Nos relatórios, descreviam muitas experiências em que os professores elaboraram coletivamente instrumentos de avaliação, aplicaram e discutiram os resultados. Assim, perceberam que a avaliação faz parte do processo de ensino; que é preciso considerar os resultados 
dela para orientar o planejamento e garantir que a aprendizagem ocorra.

O curso possibilita um repensar sobre a concepção de avaliação. [...] A análise da avaliação diagnóstica foi uma atividade interessante porque os professores tinham realizado a correção da Provinha Brasil no início de abril. (Neiva Xavier Barasuol).

Além de citarem temas mais relacionados aos conteúdos curriculares, os orientadores de estudo também foram sensíveis a dimensões mais subjetivas do processo de ensino e aprendizagem que só são visíveis por meio de análises mais minuciosas da prática. As situações de análise de cenas de sala de aula videogravadas e as discussões baseadas em relatos orais dos próprios participantes favoreceram, segundo os cursistas, a percepção de que é necessário ser um mediador comprometido e atento para que a aprendizagem ocorra.

Compreensão de que o professor pode trabalhar o desenvolvimento de diferentes habilidades por meio de estratégias de leitura e para tanto é necessário que o professor seja mediador interagindo com seu aluno (comentando o texto, questionando, mobilizando o conhecimento de mundo para que o aluno faça suas previsões sobre o texto). (Adriane Angheben Eitelven).

Durante as reflexões, as cursistas perceberam que devem oferecer o acesso à leitura prazerosa e útil ao aluno, sendo mediadoras e valorizando outras mediações - familiares, amigos e colegas. (Lília Jurema Monteiro Masson).

Na esteira dos aspectos mais subjetivos citados pelos orientadores de estudo, encontramos também trechos que explicitavam que os professores, por meio da formação continuada, consolidaram mais as preocupações com o planejamento de aula, reafirmando a ideia de que para conduzir um ensino de qualidade é necessário ter clareza sobre os objetivos didáticos a serem atingidos.

Durante a realização da atividade, as professoras comentavam sobre a importância da atividade e, segundo suas próprias palavras, perceberam que o exercício trabalhado em aula não pode ser um mero preenchedor de tempo, mas tem que ter objetivo claro, querer alguma coisa com a atividade. (Cleci Ávila Bitencourt).

A teorização das práticas a partir do descobrimento ou reconhecimento das capacidades linguísticas e a exploração dos quadros de capacidades a partir da análise de algumas atividades permitiram aos cursistas perceberem que em seus planejamentos não se davam conta de quais capacidades estavam sendo contempladas. (Patrícia Geyer).

\section{Considerações finais}

As análises dos relatórios dos orientadores de estudo mostraram que muitos aspectos positivos foram indicados por eles. Foram explicitados 
princípios didáticos apreendidos ou consolidados pelos professores no processo formativo. Neste artigo, pretendíamos, mediante essas análises, mostrar que na formação continuada podemos promover situações ricas de aprendizagem coletiva por meio da teorização da prática. A garantia de tempo para reflexão e debate, objetivados a partir de situações estruturadas, planejadas, pode trazer mudanças de diferentes níveis na prática pedagógica de professores.

Nos relatórios analisados, várias referências à importância da formação continuada foram encontradas. A mais recorrente era a de que a formação de professores precisa ser contínua. De fato, a permanência de um determinado grupo que troca experiências é salutar, pois, além de desenvolver confiança mútua para que possa externalizar angústias, dúvidas, incertezas, também pode recorrer a discussões anteriores para ancorar novos debates.

Outro princípio citado foi que é preciso planejar estratégias formativas reflexivas, descontraídas e participativas.

Todo o curso foi um momento de reflexão, descontração e aprendizagem. (Fatiana Pereira de Vasconcelos).

Foi importante a troca de experiências entre as cursistas que preferem os trabalhos em grupo. (Ângela Hermes).

Houve troca de experiência entre os cursistas. (Fernanda Rodrigues Zanatta).

A formação dos grupos de estudos é uma forma de dividir conhecimento e experiências pedagógicas. As trocas de experiências trouxeram importantes contribuições para a prática, possibilitando o repensar sobre os espaços destinados à leitura em sala de aula. (Sílvia Regina Cavalheiro Zangirolami).

Os orientadores indicaram também terem percebido que, para os professores se sentirem motivados a participar de encontros de formação continuada, é necessário contar com recursos didáticos de boa qualidade.

O material disponibilizado pelo programa e a exposição dialogada sobre os conceitos de alfabetização e letramento e alfabetizar letrando sanaram as dúvidas que surgiram. (Patrícia Geyer).

Enfim, os orientadores perceberam que um bom projeto de formação continuada estimula a disposição para mudança.

Para mim, o trabalho de tutor exige comprometimento, responsabilidade e dedicação, mas tudo isso se torna gratificante quando os cursistas falam que estão colocando em prática atividades do curso, ou seja, mudando sua prática. (Anelori Keller).

Os cursistas assumem que precisam mudar o seu trabalho em diversos aspectos. (Marisa Teresinha Gonçalves de Freitas).

Surpreendi-me com a disponibilidade das participantes em contribuir para que mudanças aconteçam, que problemas sejam resolvidos e que 
as conquistas sejam de todos, beneficiando os principais personagens de nossa jornada, ou seja, nossos alunos. (Marinês Zarichta).

Desse modo, os extratos dos relatórios acima nos apontam que, nas formações continuadas, é importante valorizar os professores e seus saberes para que eles possam se descobrir enquanto sujeitos inacabados e capazes de aprender e pensar sempre sobre a sua prática e modificá-la de modo a favorecer o aprendizado dos seus alunos reais.

Por fim, ressaltamos que, apesar de analisarmos uma experiência específica, destacando as temáticas e estratégias formativas, valorizadas pelos docentes que assumiam a função de orientadores de estudo, não tomamos esta experiência como modelo a ser seguido ou como um único caminho a ser percorrido para garantir processos de formação continuada em que saberes múltiplos sejam construídos e reconstruídos.

Na verdade, pretendíamos valorizar a voz dos que, na escola, buscavam de modo comprometido, responsável e desafiador promover momentos ricos de interação coletiva. Os orientadores de estudo, muitos ainda iniciantes nesta função de "desenvolver experiências de formação docente", evidenciaram capacidade de favorecer, entre seus pares, situações de aprendizagem ancoradas em saberes construídos no cotidiano da escola.

Muitas diferenças foram observadas nas estratégias adotadas pelos orientadores, resultantes das diferentes experiências vivenciadas por eles próprios e pelos que estavam compartilhando os momentos de aprendizagem coletiva. Havia, assim, segundo os relatos analisados, socialização e teorização acerca dessas diferentes experiências. Tal princípio é importante porque, como defende Ferraço (2008, p. 17),

qualquer pretensão de engessar sentidos ou de estabelecer trilhos de pensamentos a serem seguidos é, sumariamente e todo tempo, violada pelos movimentos das redes cotidianas de saberesfazeres, que produzem danças e deslizamentos de significados impossíveis de serem previstos ou controlados.

\section{Referências bibliográficas}

BAKHTIN, Mikhail. Marxismo e filosofia da linguagem. 12. ed. São Paulo: Hucitec, 1998.

CHARTIER, Anne-Marie. A questão da língua materna na formação continuada entre os anos 1970 e 2010 na França. In: FERREIRA, Andrea Tereza Brito; CRUZ, Shirleide Pereira da Silva. Formação continuada de professores: reflexões sobre a prática. Recife: Ed. UFPE, 2010.

.Práticas de leitura e escrita: história e atualidade.

Belo Horizonte: Autêntica, 2007. 
FERRAÇO, Carlos Eduardo. Currículo, formação continuada de professores e cotidiano escolar: fragmentos de complexidade das redes vividas. In: FERRAÇO, Carlos Eduardo. Cotidiano escolar, formação de professores(as) e currículo. 2. ed. São Paulo: Cortez, 2008.

FERREIRA, Andrea Tereza Brito. Os saberes docentes e sua prática. In: FERREIRA, Andrea Tereza Brito; ALBUQUERQUE, Eliana Borges Correia de; LEAL, Telma Ferraz (Org.). Formação continuada de professores: questões para reflexão. Belo Horizonte: Autêntica, 2005.

GERALDI, João Wanderley. Prática da leitura na escola. In: GERALDI, João Wanderley (Org.). O texto na sala de aula. 3. ed. São Paulo:

Ática, 2003.

GOIGOUX, Roland. Concevoir un instrument didactique pour améliorer l'enseignement de la comprehension de textes: les rates de l'apprentissage de la lecture à l'école et au collège. Repères, Lyon,

n. 35, 2007.

Méthodes et pratiques d'enseignenment de la lecture.

Formation et Pratiques d'Enseignement en Questions, Suisse, n. 1, p. 37-56, 2004.

HOUPERT, Danielle. Quels principes pour la formation continue? Enseigner, un métier qui s'apprend. Cahiers pédagogiques, n. 435, p. 45-49, 2005.

LEAL, Telma Ferraz; GUIMARÃES, Gilda Lisboa; SILVA, Ana Cristina. Análise de um processo de formação de professores sobre produção de textos. In: GUIMARÃES, Gilda Lisboa; LEAL, Telma Ferraz. Formação continuada de professores. Recife: Bagaço, 2001.

MARCUSCHI, Luis Antônio. Gêneros textuais: definição e funcionalidade. In: DIONÍSIO, Angela Paiva; MACHADO, Anna Rachel; BEZERRA, Maria Auxiliadora (Org.). Gêneros textuais e ensino. Rio de Janeiro: Lucerna, 2005.

NÓVOA, Antonio (Org.). Vida de professores. Porto, Portugal: Porto Ed., 1995.

SOLÉ, Isabel. Estratégias de leitura. 6. ed. Porto Alegre, Artmed, 1998.

TARDIF, Maurice. Os professores enquanto sujeitos do conhecimento: subjetividade, prática e saberes no magistério. In: CANDAU, Vera Maria Ferrão. Didática, currículo e saberes escolares. Rio de Janeiro: DP \& A, 2000. 
Telma Ferraz Leal, doutora em Psicologia pela Universidade Federal de Pernambuco (UFPE), é professora do Departamento de Métodos e Técnicas de Ensino da Universidade Federal de Pernambuco (UFPE) e da Pós-Graduação em Educação.

tfleal@terra.com.br

Andrea Tereza Brito Ferreira, mestre em Educação pela Universidade Fdereal de Pernambuco (UFPE), é professora do Departamento de Educação da Universidade Federal Rural de Pernambuco (UFRPE) e da Pós-Graduação em Educação da UFPE.

atbrito@superig.com.br

Recebido em 26 de setembro de 2010.

Aprovado em 25 de abril de 2011. 